\title{
Pancreatic Necrosectomy through Sinus Tract Endoscopy
}

\author{
Mahesh Kumar Goenka ${ }^{1}$, Usha Goenka ${ }^{2}$, Md.Yasin Mujoo ${ }^{1}$, Indrajit Kumar Tiwary ${ }^{1}$, Sanjay Mahawar' ${ }^{1}$ and Vijay Kumar Rai ${ }^{1}$ \\ ${ }^{1}$ Institute of Gastrosciences, ${ }^{2}$ Department of Clinical Imaging and Interventional Radiology, Apollo Gleneagles Hospitals, Kolkata, India
}

Background/Aims: Direct endoscopic pancreatic necrosectomy is increasingly being utilized to treat infected or symptomatic walledoff necrosis (WON) located close to the stomach or duodenum. Laterally-placed WON has traditionally been treated surgically. We evaluated a less utilized technique of sinus tract endoscopy (STE) for symptomatic laterally-placed WON.

Methods: Two hundred seventy-six patients with acute pancreatitis admitted in our hospital, 32 had symptomatic or infected WON requiring intervention. Of the 12 patients with laterally placed WON, 10 were treated by STE. STE was performed with a standard adult gastroscope passed through a percutaneous tract created by the placement of a 32-Fr drain.

Results: Ten patients ( 7 males; mean age, 43.8 years) underwent STE. Mean number of sessions was 2.3 (range, 1-4), with mean time of 70 minutes for each session (range, 15-70 minutes). While 9 patients had complete success, 1 patient had fever and chose to undergo surgery. Two patients developed pneumoperitoneum, which was treated conservatively. There was no mortality, cutaneous fistula, or recurrence during follow-up.

Conclusions: Laterally placed WON can be successfully managed by STE performed through a percutaneously placed drain. Details of the technique and end-points of STE require further evaluation. Clin Endosc 2018;51:279-284

Key Words: Walled-off necrosis; Pancreatitis, acute necrotizing; Sinus tract endoscopy; Necrosectomy

\section{INTRODUCTION}

Most patients with acute pancreatitis have mild disease and recover without any sequelae. However, acute necrotizing pancreatitis is often associated with significant morbidity and mortality, which can vary from $10 \%$ to $40 \%$ depending on the extent of pancreatic necrosis and the presence or absence of infection. $^{1-8}$

With a better understanding of the pathophysiology and natural history of severe acute pancreatitis, many patients with infected pancreatic necrosis are being treated non-surgi-

Received: May 6, 2017 Revised: July 19, 2017

Accepted: September 13, 2017

Correspondence: Mahesh Kumar Goenka

Institute of Gastrosciences, Apollo Gleneagles Hospitals, 58 Canal Circular Road, Kolkata 700054, India

Tel: +91-33-2320-3040, Fax: +91-33-2320-5218, E-mail: mkgkolkata@gmail.com ORCID: https://orcid.org/0000-0003-1700-7543

(c) This is an Open Access article distributed under the terms of the Creative Commons Attribution Non-Commercial License (http://creativecommons.org/ licenses/by-nc/3.0) which permits unrestricted non-commercial use, distribution, and reproduction in any medium, provided the original work is properly cited. cally. ${ }^{9-16}$ Endoscopic drainage of walled-off necrosis (WON), either by placement of stents or by direct endoscopic necrosectomy (DEN), is being increasingly used..$^{9-13}$ Because of its higher success rate, lower morbidity and mortality, and shorter hospital stay, DEN is now considered an intervention of choice for WON that is centrally located, i.e., close to the stomach or duodenum. ${ }^{9-13}$ Laterally placed WON, which is distant from the stomach or duodenum, ${ }^{14}$ cannot be approached through the gastroduodenal lumen and has traditionally been treated by surgery. In this observational, cross-sectional study, we report our experience of treating laterally placed WON by endoscopic necrosectomy through a sinus tract created percutaneously.

\section{MATERIALS AND METHODS}

\section{Patient cohort}

A total of 276 patients with acute pancreatitis were admitted in our institute during a period of 3 years (January 2014 


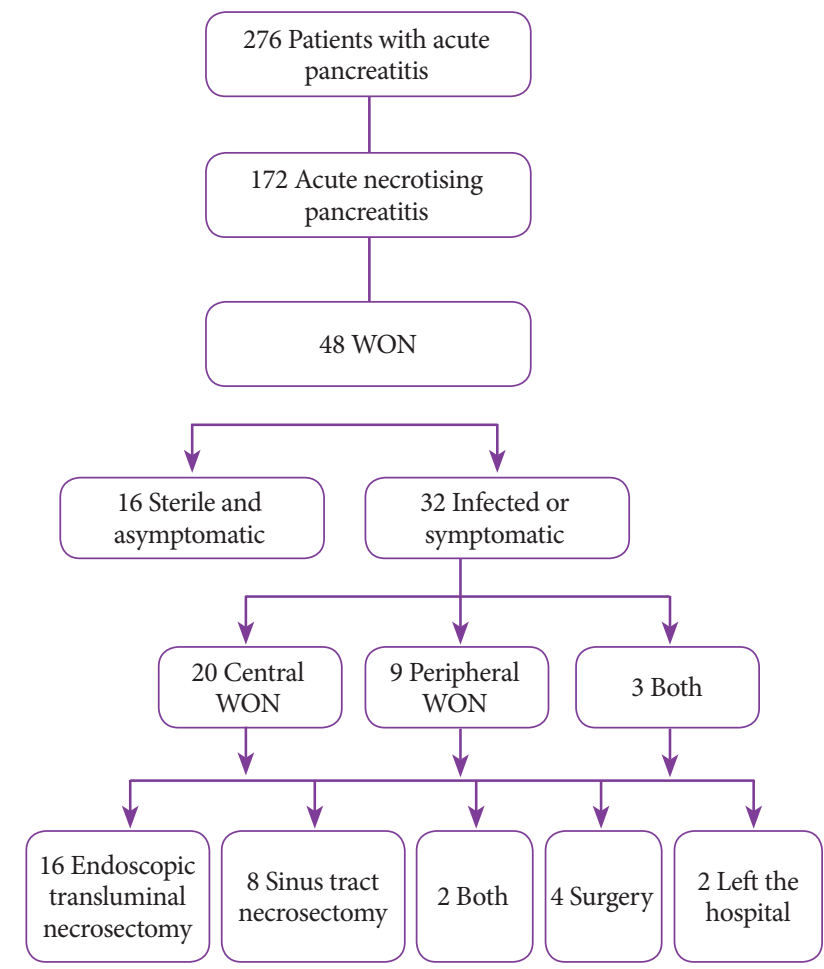

Fig. 1. Outcome of patients admitted with acute pancreatitis. WON, walled-off necrosis.

to December 2016). Of these, 186 were admitted early in their clinical course (within 5 days of diagnosis), and 90 were transferred to our care due to non-resolution of symptoms or development of complications. A total of 172 patients were diagnosed with acute necrotizing pancreatitis on the basis of computed tomography (CT). As shown in Fig. 1, 48 patients were diagnosed with WON, and 32 had indications for intervention due to sepsis, abdominal pain, or vomiting. Of these 32 patients, 20 had centrally placed WON, 9 had laterally placed WON, and 3 had both central and lateral WON. Laterally placed WON was defined as one located lateral to the stomach and duodenum, with at least $2 \mathrm{~cm}$ distance between the WON and the wall of the stomach or duodenum. ${ }^{14}$ Endoscopic necrosectomy was offered to all 32 patients, but only 26 patients, including 10 of 12 with laterally placed WON, gave their consent. These 10 patients were subjected to sinus tract endoscopy (STE). The study was approved by the Institutional Review Board.

\section{Technique of sinus tract endoscopy}

Once a decision was made to perform STE, the radiologist (UG) placed a percutaneous drainage catheter with CT guidance under local anesthesia. After deciding the point of entry and a safe track, a small skin incision was made and the track was dilated using arterial forceps. A trocar drain was then positioned. A 32-Fr catheter was placed in 8 patients at the initial session, while 2 patients initially had a drain of smaller size that was subsequently replaced by a $32-\mathrm{Fr}$ catheter. STE was carried out at least 10 days after the placement of the 32Fr catheter in order to allow the tract wall to mature.

STE was performed under fluoroscopic guidance with intravenous propofol anesthesia in the presence of an anesthetist (IKT and SM). A pediatric gastroscope (GIFXP 160; Olympus Co., Tokyo, Japan) with an outer diameter of $5.9 \mathrm{~mm}$ was first passed through the drain tube for initial assessment. The drain catheter was then removed, and an adult gastroscope (GIF 160/180/190; Olympus Co.) with an outer diameter of approximately $9 \mathrm{~mm}$ was introduced carefully into the necrotic cavity under fluoroscopic control. This procedure was performed with carbon dioxide insufflation. The liquid content of WON was aspirated, and the cavity was lavaged with sterile normal saline, which was also sucked out. Necrotic tissue was removed using various endoscopic accessories such as rat-tooth forceps, Roth basket, polypectomy snare, and Dormia basket. Both necrotic materials lying free in the cavity as well as attached to the wall were extracted by gently pulling on the tissue.

The first session was terminated after all loose tissues were removed and the attempt to remove attached necrotic tissue failed or initiated mild ooze. About $100 \mathrm{~mL}$ of hydrogen peroxide (diluted 3 times with saline) was instilled into the cavity at the end of the procedure, and a 32-Fr catheter was reintroduced through the sinus tract into the cavity under fluoroscopic guidance. The procedure was repeated at an interval of 2-5 days until the end-point was reached. The primary outcome was clinical success, defined as control of symptoms associated with near complete clearance of necrotic tissue and visualization of healthy granulation tissue lining the wall of the cavity. Other outcome parameters included technical procedural success and adverse effects. The drainage tube was kept in place until the output was less than $10 \mathrm{~mL} /$ day and was then withdrawn. Fig. 2 illustrates a patient undergoing STE. Antibiotics were continued until the drain tube was removed. Follow-up CT was performed in 7 patients. None of the patients underwent endoscopic retrograde cholangiopancreatography (ERCP).

\section{RESULTS}

A total of 10 patients underwent STE for pancreatic necrosectomy. The indication for drainage was infection in 6 patients and significant pain in 4 patients. Table 1 gives the details of these 10 patients along with their outcomes. The mean age of the patients in this series was 43.8 years (range, 29 to 55 years) with a male:female ratio of 7:3. The follow-up period was 3 to 12 months. Pancreatitis was caused by a gall- 

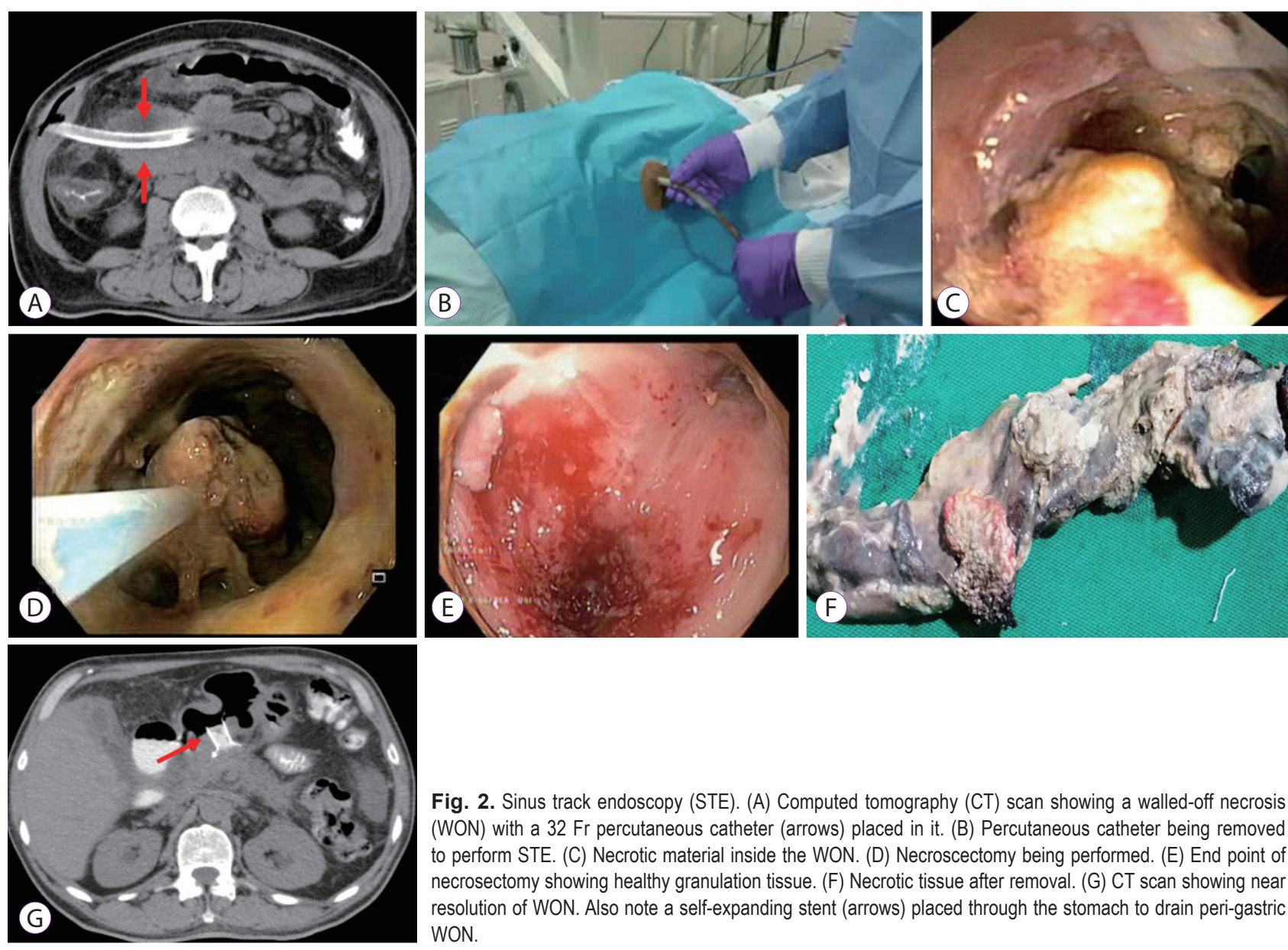

Fig. 2. Sinus track endoscopy (STE). (A) Computed tomography (CT) scan showing a walled-off necrosis (WON) with a $32 \mathrm{Fr}$ percutaneous catheter (arrows) placed in it. (B) Percutaneous catheter being removed to perform STE. (C) Necrotic material inside the WON. (D) Necroscectomy being performed. (E) End point of necrosectomy showing healthy granulation tissue. (F) Necrotic tissue after removal. (G) CT scan showing near resolution of WON. Also note a self-expanding stent (arrows) placed through the stomach to drain peri-gastric WON.

Table 1 . Patient Demography as well as Details of Sinus Track Endoscopy and Its Outcome

\begin{tabular}{|c|c|c|c|c|c|c|c|c|c|}
\hline No & Age & Sex & Etiology & CTSI & $\begin{array}{c}\text { Hospital } \\
\text { stay (days) }\end{array}$ & $\begin{array}{c}\text { No. of } \\
\text { sessions }\end{array}$ & $\begin{array}{l}\text { Drain } \\
\text { size }\end{array}$ & Success & Complications \\
\hline 1 & 55 & Male & Gall stone & 8 & 18 & 2 & $32 \mathrm{~F}$ & Yes & Nil \\
\hline 2 & 38 & Male & Alcohol & 10 & 44 & 3 & $32 \mathrm{~F}$ & Yes & Nil \\
\hline 3 & 50 & Male & Nil & 7 & 20 & 1 & $32 \mathrm{~F}$ & Yes & Peumo \\
\hline 4 & 55 & Male & Gall stone & 8 & 35 & 4 & $32 \mathrm{~F}$ & Yes & Peumo \\
\hline 5 & 29 & Male & Traumatic & 10 & 21 & 3 & $32 \mathrm{~F}$ & Yes & Nil \\
\hline 6 & 37 & Male & Alcohol & 6 & 30 & 2 & $32 \mathrm{~F}$ & Partly $^{\text {a) }}$ & Nil \\
\hline 7 & 36 & Female & Gall stone & 7 & 22 & 1 & $32 \mathrm{~F}$ & Yes & Nil \\
\hline 8 & 45 & Female & Gall stone & 8 & 18 & 2 & $32 \mathrm{~F}$ & Yes & Nil \\
\hline 9 & 38 & Female & Nil & 8 & 18 & 2 & $32 \mathrm{~F}$ & Yes & Nil \\
\hline 10 & 52 & Male & Alcohol & 8 & 19 & 3 & $32 \mathrm{~F}$ & Yes & Nil \\
\hline
\end{tabular}

CTSI, computed tomography severity index.

${ }^{\text {a) }}$ Patient underwent surgical necrosectomy.

stone in 4 patients, alcohol in 3, trauma in 1, and unknown reasons in 2. The overall mean CT severity index was 8 (range, 6-10) (Table 1). The size of WON varied from 4 to $12 \mathrm{~cm}$ (mean $7.2 \mathrm{~cm}$ ). Only 3 patients had organ failure (respiratory) requiring support. All patients received intensive medical care including antimicrobial agents, nutritional support, and pain therapy. 
Table 2. Summary of Reported Series of Sinus Track Endoscopy for Pancreatic Necrosis

\begin{tabular}{|c|c|c|c|c|c|c|c|}
\hline Study & $\begin{array}{c}\text { No. of } \\
\text { patients }\end{array}$ & $\begin{array}{c}\text { Initial } \\
\text { intervention }\end{array}$ & $\begin{array}{c}\text { No. of STE } \\
\text { sessions }\end{array}$ & $\begin{array}{l}\text { Adjunct proce- } \\
\text { dures \& No. of } \\
\text { patients }\end{array}$ & $\begin{array}{l}\text { Hospital stay } \\
\text { (days) }\end{array}$ & $\begin{array}{l}\text { Success } \\
\text { rate }(\%)\end{array}$ & $\begin{array}{c}\text { Mortality } \\
(\%)\end{array}$ \\
\hline $\begin{array}{l}\text { Carter et al. } \\
(2000)^{29}\end{array}$ & 14 & $\begin{array}{l}\text { ON: } 4 \\
\text { PD: } 10\end{array}$ & $\begin{array}{l}\text { Mean: } 3.1 \\
\text { Range: } 2-5\end{array}$ & ERCP: 6 & $\begin{array}{l}\text { Mean: } 59.9 \\
\text { Range: } 23-213\end{array}$ & 78.6 & 14.3 \\
\hline $\begin{array}{l}\text { Mui et al. } \\
(2005)^{30}\end{array}$ & 13 & $\begin{array}{l}\text { ON: } 4 \\
\text { PD: } 9\end{array}$ & $\begin{array}{l}\text { Mean: } 5.1 \\
\text { Range: } 1-18\end{array}$ & ERCP: 9 & $\begin{array}{l}\text { Mean: } 95.5 \\
\text { Range: } 29-194\end{array}$ & 76.9 & 7.7 \\
\hline $\begin{array}{l}\text { Dhingra et al. } \\
(2015)^{31}\end{array}$ & 15 & PD: 15 & $\begin{array}{l}\text { Mean: } 4.9 \\
\text { Range: } 2-13\end{array}$ & - & $\begin{array}{l}\text { Mean: } 56 \\
\text { Range: } 21-84\end{array}$ & 93.3 & 6.7 \\
\hline $\begin{array}{l}\text { Present study } \\
\text { (2016) }\end{array}$ & 10 & PD: 10 & $\begin{array}{l}\text { Mean: } 2.3 \\
\text { Range: } 1-4\end{array}$ & $\begin{array}{c}\text { Endoscopic } \\
\text { necrosectomy: } 2\end{array}$ & $\begin{array}{l}\text { Mean: } 24.7 \\
\text { Range: } 18-44\end{array}$ & 90 & - \\
\hline
\end{tabular}

STE, sinus track endoscopy; ON, open necrosectomy; PD, percutaneous drainage; ERCP, endoscopic retrograde cholangiopancreatography.

\section{Primary treatment outcome}

The number of STE sessions required by these 10 patients varied from 1 to 4 (mean 2.3, median 2), and the time required for each session varied from 15 to 70 minutes (mean 45 minutes). Two patients with central WON underwent additional necrosectomy through the stomach, using a lumen-apposing metal stent placed at endoscopy. The hospital stay ranged from 18 to 44 days (mean 24.7 days). Nine patients (90\%) had complete resolution of symptoms and required no further interventions. However, 1 patient with continuing fever in spite of 2 sessions of STE chose to have surgery, which was successful.

\section{Additional treatment outcomes}

All procedures were technically successful. Two patients developed pneumoperitoneum during the procedure, but remained hemodynamically stable. One was treated by placing a large-bore lumbar puncture needle into the peritoneal cavity and aspirating the air. The other patient was managed conservatively. None of the patients developed significant bleeding or required blood transfusion between or after sessions. There was no worsening of failure or development of new organ failure during the STE sessions.

\section{DISCUSSION}

Surgical pancreatic necrosectomy, which is traditionally used to treat pancreatic necrosis, is associated with significant morbidity and mortality., ${ }^{3,4}$ In contrast, many studies have shown that a minimally invasive approach in acute necrotizing pancreatitis improves patient outcome and reduces hospital stay. ${ }^{15-21}$

Over the past several decades, the endoscopic method of pancreatic necrosectomy has evolved tremendously. In addition, with a better understanding of the pathophysiology of acute pancreatic fluid collections and studies favoring a con- servative approach in pancreatitis, a step-up approach is advocated in managing patients with acute necrotizing pancreatitis. ${ }^{13} \mathrm{DEN}$ after the placement of trans-mural stents is now a popular and effective method to treat WON that is close to the stomach or duodenum. ${ }^{22-26}$ However, the endoscopic method of necrosectomy is appropriate for necrotic collections in and around the pancreatic head. Laterally placed WON, i.e., more than $1-2 \mathrm{~cm}$ from the stomach or duodenal wall, is not suitable for transmural drainage. ${ }^{27}$ These laterally placed necrotic collections have been treated traditionally with a surgical approach.

The present case series of laterally placed WON has shown that conservative treatment combined with STE was effective. We had success in $90 \%$ of our patients with no significant morbidity and mortality. While many studies have reported DEN for centrally placed WON, studies using STE are sparse and limited. Table 2 shows the data from the reported studies on STE. ${ }^{28-30}$

Carter et al..$^{29}$ as well as Mui et al. ${ }^{30}$ have used STE as the primary modality as well as for residual collection after open necrosectomy. The present study is in agreement with the study by Dhingra et al., ${ }^{31}$ who used STE as an alternative to open necrosectomy. Our results for STE, with $90 \%$ success, no mortality, fewer (mean 2.3) sessions, and relatively shorter hospital stay appear to be better than those in earlier series. This could be due to the use of a different technique than previously reported. Dhingra et al. ${ }^{31}$ and Carter et al. ${ }^{29}$ initially placed an 8-12-Fr catheter and gradually upsized the catheter or dilated the tract to $10-15 \mathrm{~mm}$ using a balloon. This obviously required multiple sessions. In contrast, we performed initial drainage with a 32-Fr drainage tube in 8 of 10 patients. This facilitated endoscopic necrosectomy earlier in the course of illness. We used diluted $\mathrm{H}_{2} \mathrm{O}_{2}$ to facilitate subsequent sessions. The efficacy of $\mathrm{H}_{2} \mathrm{O}_{2}$ during DEN has been documented. ${ }^{31}$ In contrast to the study by Carter et al. ${ }^{29}$ in which general anesthesia was used, we used 
propofol sedation in all our patients. Our high success and low complication rates could also be due to our decision to stop the procedure at the first sign of mild ooze and our use of fluoroscopic control to identify any pneumoperitoneum. Moreover, we have not combined ERCP with STE. Mui et al. ${ }^{30}$ used ERCP in 9 of 13 cases. They used a pancreatic stent in 8 patients and performed stone extraction in 4. Carter et al. $^{29}$ also performed ERCP with sphincterotomy in 5 of 14 patients. STE has been used to treat postoperative fistula and is often referred to as fistuloscopy in this situation.

The technique of STE needs to be refined further, with determination of the optimum interval between sessions, endpoint during each session, and the final end-point. Moreover, the procedure we used required fluoroscopy, with its risk of radiation, was time consuming, and had a risk of hemorrhage. While we did not encounter any significant bleeding, control of bleeding would be difficult in a cavity with limited endoscopic maneuverability. Repeated introduction of an endoscope through the sinus tract may be facilitated by the development of a properly designed covered metal stent. Accessories for removal of necrotic tissue at present are not ideal and need to be optimized.

A limited number of studies have examined modalities other than open surgery or STE to treat laterally placed WON. These modalities include percutaneous radiological drainage, laparoscopic necrosectomy, and retroperitoneal endoscopic necrosectomy. ${ }^{32-37}$ In a series of 8 patients, Bucher et al. ${ }^{33}$ reported that laparoscopic necrosectomy was successful in all cases, and 7 of the 8 patients were cured in a single session. Others have also reported isolated cases of laparoscopic necrosectomy either directly into the retroperitoneum or through the transgastric route. ${ }^{33-35}$ However, greater experience and comparative studies with STE are required for better understanding of laparoscopic necrosectomy in the treatment of WON.

Percutaneous radiological drainage and lavage without active necrosectomy, either alone or in combination with endoscopic drainage, have also been used for WON.$^{36}$ However, the results are variable and there is a need to lavage several times daily for a prolonged period. Moreover, there is a potential risk of development of a pancreaticocutaneous fistula. Further studies are required to clarify whether simple percutaneous drainage can be considered as first-line treatment for laterally placed WON and whether it can be followed by STE as a step-up technique.

Minimally invasive retroperitoneal endoscopic necrosectomy is another alternative to treat laterally placed $\mathrm{WON}^{38}$ However, the procedure appears to be more invasive than STE, with a potential risk of visceral injury and hemorrhage, and also requires greater operator skills.
This study has clearly demonstrated that STE is an alternative treatment method for laterally placed WON that is not amenable to endoscopic necrosectomy. However, as this was an observational study, we cannot draw any conclusion regarding its superiority to open surgery, retroperitoneal necrosectomy, or radiological drainage.

In conclusion, STE is an important and minimally invasive endoscopic technique for the management of acute necrotizing pancreatitis complicated by laterally placed WON. In properly selected patients with infected pancreatic necrosis, STE can prevent or delay surgery with minimal complications. Sinus tract endoscopic necrosectomy can be used in step-up management of acute infected pancreatic necrosis.

\section{Conflicts of Interest}

The authors have no financial conflicts of interest.

\section{REFERENCES}

1. Besselink MG, van Santvoort HC, Boermeester MA, et al. Timing and impact of infections in acute pancreatitis. Br J Surg 2009;96:267-273.

2. Petrov MS, Shanbhag S, Chakraborty M, Phillips AR, Windsor JA. Organ failure and infection of pancreatic necrosis as determinants of mortality in patients with acute pancreatitis. Gastroenterology 2010;139:813820.

3. Whitcomb DC. Clinical practice. Acute pancreatitis. N Engl J Med 2006;354:2142-2150.

4. Gloor B, Müller CA, Worni M, Martignoni ME, Uhl W, Büchler MW. Late mortality in patients with severe acute pancreatitis. Br J Surg 2001;88:975-979.

5. Garg PK, Madan K, Pande GK, et al. Association of extent and infection of pancreatic necrosis with organ failure and death in acute necrotizing pancreatitis. Clin Gastroenterol Hepatol 2005;3:159-166.

6. Tenner S, Baillie J, DeWitt J, Vege SS; American College of Gastroenterology. American college of gastroenterology guideline: management of acute pancreatitis. Am J Gastroenterol 2013;108:1400-1415; 1416.

7. Freeman ML, Werner J, van Santvoort HC, et al. Interventions for necrotizing pancreatitis: summary of a multidisciplinary consensus conference. Pancreas 2012;41:1176-1194.

8. Werner J, Hartwig W, Hackert T, Büchler MW. Surgery in the treatment of acute pancreatitis--open pancreatic necrosectomy. Scand J Surg 2005;94:130-134.

9. Baron TH, Thaggard WG, Morgan DE, Stanley RJ. Endoscopic therapy for organized pancreatic necrosis. Gastroenterology 1996;111:755-764.

10. Seifert H, Wehrmann T, Schmitt T, Zeuzem S, Caspary WF. Retroperitoneal endoscopic debridement for infected peripancreatic necrosis. Lancet 2000;356:653-655.

11. Working Group IAP/APA Acute Pancreatitis Guidelines. IAP/APA evidence-based guidelines for the management of acute pancreatitis. Pancreatology 2013;13(4 Suppl 2):e1-e15.

12. Larvin M. Management of infected pancreatic necrosis. Curr Gastroenterol Rep 2008;10:107-114.

13. van Santvoort HC, Besselink MG, Bakker OJ, et al. A step-up approach or open necrosectomy for necrotizing pancreatitis. N Engl J Med 2010;362:1491-1502.

14. Trikudanathan G, Attam R, Arain MA, Mallery S, Freeman ML. Endoscopic interventions for necrotizing pancreatitis. Am J Gastroenterol 2014;109:969-981; quiz 982.

15. van Santvoort HC, Bakker OJ, Bollen TL, et al. A conservative and min- 
imally invasive approach to necrotizing pancreatitis improves outcome. Gastroenterology 2011;141:1254-1263.

16. Gluck M, Ross A, Irani S, et al. Endoscopic and percutaneous drainage of symptomatic walled-off pancreatic necrosis reduces hospital stay and radiographic resources. Clin Gastroenterol Hepatol 2010;8:1083-1088.

17. Ross AS, Irani S, Gan SI, et al. Dual-modality drainage of infected and symptomatic walled-off pancreatic necrosis: long-term clinical outcomes. Gastrointest Endosc 2014;79:929-935.

18. Bakker OJ, van Santvoort HC, van Brunschot S, et al. Endoscopic transgastric vs surgical necrosectomy for infected necrotizing pancreatitis: a randomized trial. JAMA 2012;307:1053-1061.

19. Mouli VP, Sreenivas V, Garg PK. Efficacy of conservative treatment, without necrosectomy, for infected pancreatic necrosis: a systematic review and meta-analysis. Gastroenterology 2013;144:333-340.e2.

20. Runzi M, Niebel W, Goebell H, Gerken G, Layer P. Severe acute pancreatitis: nonsurgical treatment of infected necroses. Pancreas 2005;30:195199.

21. Lee JK, Kwak KK, Park JK, et al. The efficacy of nonsurgical treatment of infected pancreatic necrosis. Pancreas 2007;34:399-404.

22. Hart PA, Baron TH. What is the role of noninvasive treatment for infected pancreatic necrosis: still an unanswered question. Gastroenterology 2013;144:1574-1575.

23. Seifert H, Biermer M, Schmitt W, et al. Transluminal endoscopic necrosectomy after acute pancreatitis: a multicentre study with long-term follow-up (the GEPARD study). Gut 2009;58:1260-1266.

24. Charnley RM, Lochan R, Gray H, O'Sullivan CB, Scott J, Oppong KE. Endoscopic necrosectomy as primary therapy in the management of infected pancreatic necrosis. Endoscopy 2006;38:925-928.

25. Rische S, Riecken B, Degenkolb J, Kayser T, Caca K. Transmural endoscopic necrosectomy of infected pancreatic necroses and drainage of infected pseudocysts: a tailored approach. Scand J Gastroenterol 2013;48:231-240.

26. Escourrou J, Shehab H, Buscail L, et al. Peroral transgastric/transduodenal necrosectomy: success in the treatment of infected pancreatic necrosis. Ann Surg 2008;248:1074-1080.

27. Yasuda I, Nakashima M, Iwai T, et al. Japanese multicenter experience of endoscopic necrosectomy for infected walled-off pancreatic necrosis: The JENIPaN study. Endoscopy 2013;45:627-634.

28. Gardner TB. Endoscopic management of necrotizing pancreatitis. Gastrointest Endosc 2012;76:1214-1223.

29. Carter CR, McKay CJ, Imrie CW. Percutaneous necrosectomy and sinus tract endoscopy in the management of infected pancreatic necrosis: an initial experience. Ann Surg 2000;232:175-180.

30. Mui LM, Wong SK, Ng EK, Chan AC, Chung SC. Combined sinus tract endoscopy and endoscopic retrograde cholangiopancreatography in management of pancreatic necrosis and abscess. Surg Endosc 2005;19:393-397.

31. Dhingra R, Srivastava S, Behra S, et al. Single or multiport percutaneous endoscopic necrosectomy performed with the patient under conscious sedation is a safe and effective treatment for infected pancreatic necrosis (with video). Gastrointest Endosc 2015;81:351-359.

32. Abdelhafez M, Elnegouly M, Hasab Allah MS, Elshazli M, Mikhail HM, Yosry A. Transluminal retroperitoneal endoscopic necrosectomy with the use of hydrogen peroxide and without external irrigation: a novel approach for the treatment of walled-off pancreatic necrosis. Surg Endosc 2013;27:3911-3920.

33. Bucher P, Pugin F, Morel P. Minimally invasive necrosectomy for infected necrotizing pancreatitis. Pancreas 2008;36:113-119.

34. Ammori BJ. Laparoscopic transgastric pancreatic necrosectomy for infected pancreatic necrosis. Surg Endosc 2002;16:1362.

35. Horvath KD, Kao LS, Ali A, Wherry KL, Pellegrini CA, Sinanan MN. Laparoscopic assisted percutaneous drainage of infected pancreatic necrosis. Surg Endosc 2001;15:677-682.

36. Horvath KD, Kao LS, Wherry KL, Pellegrini CA, Sinanan MN. A technique for laparoscopic-assisted percutaneous drainage of infected pancreatic necrosis and pancreatic abscess. Surg Endosc 2001;15:1221-1225.

37. Freeny PC, Lewis GP, Traverso LW, Ryan JA. Infected pancreatic fluid collections: percutaneous catheter drainage. Radiology 1988;167:435441.

38. Gambiez LP, Denimal FA, Porte HL, Saudemont A, Chambon JP, Quandalle PA. Retroperitoneal approach and endoscopic management of peripancreatic necrosis collections. Arch Surg 1998;133:66-72. 